\title{
Increasing Learning Motivation and Student Engagement through the Technology- Supported Learning Environment
}

\author{
Yung-Ting Chuang \\ Department of Information Management, National Chung Cheng University, Chia-Yi County, Taiwan \\ Email: ytchuang@mis.ccu.edu.tw
}

Received 3 October2014; revised 31 October 2014; accepted 16 November 2014

Copyright @ 2014 by author and Scientific Research Publishing Inc. This work is licensed under the Creative Commons Attribution International License (CC BY). http://creativecommons.org/licenses/by/4.0/

\begin{abstract}
Education is one of the most important elements in our lives because it is a direct way to broaden our knowledge. In order to enhance academic learning experience, an increasing number of instructors are changing their pedagogies to make their students socially active in class participation. In this article, the author describes how the development and implementation of the technology-supported learning environment will be beneficial in student and instructor engagement and the overall learning motivation. The author first provides detailed implementation of the technology-supported learning environment. Next, she explains how to utilize such environment to increase in-class participation and to support collaborative learning. She then examines students' overall learning and feedback, and analyzes the costs and benefits of this pedagogy. Finally, she concludes that this environment can promote greater classroom engagement and support collaborative learning.
\end{abstract}

\section{Keywords}

Instructional Design, Group Activities, Collaborative Learning, Surveys/Feedbacks, Technology

\section{Introduction}

Teaching is the fundamental mission of any university or college. The creation of new knowledge is of little value without the ability to pass on that new knowledge, and existing knowledge, to the next generation. It is important to understand how students learn and to know when they might confront difficulties with new concept. For past decades, traditional lecturing has used an instructor-oriented approach, where the majority of the class time depends on the instructor's delivery of knowledge. The drawback of such lecturing is that there is little interaction between instructors and students, as students tend to engage only passively with the material. Several 
scholars believe that instructors focus too much on teaching content and not on engaging students on traditional lecturing. As a result, it is hard to find out the difficulties that students might encounter, and thus, students must be actively engaged in the learning process in order to have a meaningful and long-lasting learning experience (Barkley et al., 2014; Pascarella et al., 2005; Edgerton, 1997; Shulman, 2002).

Interactive lecturing, on the other hand, includes short activities that allow students to recall and enhance their knowledge. The benefits of interactive lecturing include greater in-class engagement and collaborative learning. Collaborative learning, by definition, means that students achieve their learning goals via a group-based approach (Dillenbourg et al., 1995). Some benefits of collaborative learning include enhancing learning satisfaction, promoting positive attitudes toward subject matter, improving students' teamwork skills, encouraging more in-class participation, promoting greater in-class attention, creating more in-class interaction, and developing higher-order thinking (Srinivas, 2014).

Since technology has become integrated into in our daily life, interactive lecturing with technology has become a groundbreaking advancement in education. According to Kuh et al. (2001), technology has been proven to improve learning outcomes and engagement. Some scholars (Meyers et al., 1993) believe that higher-order thinking, which facilitates students' knowledge development, is an important concept in education and can ultimately achieve collaborative learning. Thus, it is important to utilize these learning technologies, such as CSCL (computer-supported collaborative learning), to support group collaboration and achieve collaborative learning (Stahl et al., 2006). As a result, I decide to utilize learning technologies so that I can transition my pedagogy from an instructor-centered passive learning environment to a student-centered active learning environment.

The main purpose of this paper is to introduce a technology-supported environment to promote in-class participation and achieve collaborative learning. My contribution includes: 1) discussing the reasons that have made me to make this change; 2) explaining how I implement this technology-supported learning environment; 3) introducing how I utilize these technologies to encourage greater in-class participation and collaborative learning; and 4) analyzing and discussing the effectiveness of this pedagogy.

\section{The Necessity of Promoting In-Class Participation and Achieving Collaborative Learning}

One of my initial obstacles in becoming an instructor was that I did not know how to encourage student participation. It was a huge challenge for me especially when I was teaching Asian students since they were trained to remain silent in class and follow exactly what instructors tell them to do. That can cause a trend in student learning behavior that is skewed toward self-consciousness. For example, most of the students in Taiwan do not like to speak up in front of the whole class because they are unsure about themselves and feel very uncomfortable to present themselves in public.

Luckily, I was fortunate to join the SST (School of Scientific Thought) program in 2012, in which I attended four useful training session and learned how to actively engage the class participation. In the first session, the coordinators shared some of the experiences from previous years. The coordinators shared us some issues they had encountered in the past and how they solved those problems. In the second session, they taught us how to create our teaching materials appropriately to better suit the students' prior knowledge, as well as how to manage our time for the lectures and in-class activities. They also suggested some ways for us to utilize in-class activities to engage more student participation. During the lunch break, the SST coordinators invited some past SST instructors to talk about their teaching experience. In the third session, I had to pair up with one of the SST instructors and conduct an in-class activity in front of the class. This SST exercise trained me to help me to see how students learn better through class participation. In the last session, each instructor had to simulate a real classroom setting by giving a 60-minute presentation and obtaining comments from other SST instructors after the presentation. Honestly, encouraging student participation was one of my weaknesses before these SST training sessions, and I indeed sharpen my teaching skills from attending these sessions. I was intrigued by these SST training session and had begun to think about how I can increase student engagement in my class. In other words, I believe that by making this change, I can engage both myself and my students with my teaching materials, and can encourage overall classroom engagement.

\section{Collaborative Learning}

Collaborative learning is one of the important factors that every instructor should emphasize as they develop 
their teaching pedagogy. By definition, collaborative learning defines as to have students to work together in a small group and to achieve learning goals together. Collaborative learning is a shift from traditional instructororiented lecturing to interactive student-oriented lecturing (Kirschner, 2001), and it improves test results and promotes students' interest and motivation in learning (Caldwell, 2007; Pollock, 2006; Sharan, 1980). In addition, Hake (2001) and Gabbert et al. (1986) note that group discussions help students learn better, understand subject matter more quickly, and become more engaged in the class.

Most scholars believe that social interaction a key component in collaborative learning, and there is a large benefit to applying collaborative learning. Some scholars believe that students can develop cognition through social interaction (Vygotsky, 1980; Pascarella et al., 2005; Edgerton, 1997; Shulman, 2002) and can retain information longer through social interaction (Sills et al., 1991). Other scholars consider that collaborative learning strengthens critical thinking and deep learning, as critical thinking encourages students' judgment and problem-solving skills (Gokhale, 1995; McLoughlin et al., 2000; Newman et al., 1995). Moreover, some people believe that the overall learning performance is related to students' interaction with their peers (Barron, 2003; Bruffee, 1999).

Therefore, I have established my teaching pedagogy to support collaborative learning and promote greater engagement. My teaching pedagogy includes incorporating technology-supported environment, constructing inclass activities to encourage in-class participation, and dynamically adjust teaching methods based on their feedback and reactions. I hope that in this way it would stimulate students' learning motivation and ultimately achieve learning goals together.

\section{Experimental Setting}

My experimental course is called “iTrust: Centralized, Distributed, and Mobile Search", and there are 22 highschool students in the class. In this course, students need to understand the differences between centralized and distributed search engine, identify their trade-offs, explore the iTrust gadgets (desktop, cell phones, and tablets), understand simple statistical equations behind iTrust, learn how iTrust detect/defend some possible attacks over the network, and finally learn how we retrieve and rank the information. The goal of this course is to teach these high school students in the area of science and engineering at a college level, and the topics ranged from nanotechnology to real life situations. In my course, I taught my students the following topics:

Week 1: Concept of a distributed search engine and its comparison to existing centralized search engines.

Week 2: Trade-off between distributed and centralized search engines.

Week 3: Construction of a distributed search engine in SMS and HTTP.

Week 4: Calculating the probability of matching keywords in a query and metadata for a document.

Week 5: Detection of malicious attacks in our distributed search network.

In order to adapt the technology-supported learning environment, I perform my teaching practice in a lab classroom, whereas every students gets to have his/her own computer to perform some in-class activities. In addition, my students also have chances to access the iTrust gadgets (tablets and smart phones). I always introduce the class materials during the first hour, followed by in-class activities for students to discuss the lecture materials. After in-class activities are over, students will share their solutions to the entire class, and I will then elaborate some discussions.

\section{Student Learning Goals}

There are three main learning goals to support collaborative learning and promote greater engagement:

1) Utilizing technology-supported environment. Based on recent advance in internet access and mobile phones, many technology-enabled learning environments are being introduced. According to Fisher (2010), he believes that traditional lecturing environment is like a closed classroom that represents a physically outdated teaching model. Fisher collects more than $85 \%$ of the positive feedback about utilizing technology-enabled active learning classrooms. The interviewees also believe that technology-enabled learning active environment improves the overall learning outcomes, such as greater engagement, attitude and collaboration. Thus, I believe that having students to learn in a technology-enabled classroom will definitely increase both learning motivations and learning outcomes.

2) Encouraging fully in-class participation. In general, class participation allows students to enhance their learning opportunities. Thus, students can get motivated and collaborated with others to learn things together 
when they fully participate in the class. However, having students to actively participated in the class was a huge challenge especially when I teach Asian students, since they were trained to remain silent in class and follow exactly what instructors tell them to do. That can cause a trend in student learning behavior that is skewed toward self-consciousness. By trial and error, I figured out that the best way to encourage in-class participation is to assign some in-class activities during my lecture and ask my students to form small groups and work on problems together. Since in-class activities is a form of engaged learning, it allows my students to take classroom leadership in a ways that are not possible in traditional lecture-style classroom, and thus would inspire more learning motivation (Hertel et al., 2002).

3) Adjusting lecture contents based on students' feedback. Students would learn best if I adjust my teaching methods dynamically based on their feedback and reactions. From my past experiments, continuous feedback and assessment throughout the class are needed in order to adjust my lecture contents more promptly. For example, if I realized that the level of difficulty was too high for my students, I modified those problems accordingly. Moreover, at the end of my class, I asked my students to complete an evaluation for both the class contents and myself. By doing so, I had a better idea of how they responded to the materials and, consequently, I altered my teaching materials for the following week. In addition, I can determine whether the pace of my lecture and adjust the pace promptly.

In summary, having technology-enabled learning environment, actively engaging in-class participations, and acquiring continuous feedbacks are very critical processes to encourage learning motivation and to obtain collaborative learning. Since teaching and learning is a mutual process, not only do students learn from me, but they also provide me with feedback on my overall teaching performance. By providing the above-mentioned processes, students would increase their interests, and thereby encouraging in-class participation. Once my students are not afraid of actively participate in my class, they would definitely provide comments and feedback. The more feedback I obtain, the better I can understand how students learn and think, and can adaptively adjust my teaching methods accordingly. By doing so, students will be highly get motivated to learn and, be able to apply the concepts to the real world.

\section{Analysis and Discussions}

I was fortunate to gather feedback from teaching in the SST course at the end of each course. For each week, I generated a set of questions related to class material during that particular week and students had to complete the questions before they left the class. I will evaluate the class activities, class load, level of difficulty, and overall class ratings for the following subsections.

\subsection{Evaluation of Class Activities}

1) Positive feedback

- "Yes, very helpful and fun too."

- "Today's activities are helpful to understand because we get to learn the materials."

- "Yes, I think they are helpful and I can't wait to use it at home."

- "Yes, very helpful because will help in future."

- "Today was very interesting and informative, thank you!"

- "Yes they are helpful because they help us improve our knowledge."

- "Today's activities were helpful because speaking in front of everybody motivates me to work."

- "I think the class activity do help me learn. I like how you tell us about it and then we work on it."

- "Yes because it is a good practice."

- "I believe it was helpful because it taught me to work in group and make it easier."

- "Yes, I learned to work with a partner and he helped me."

- "Yes the class activity is helpful. It allows me to work with others to solve a problem."

2) Constructive feedback

- "I think today's activity was confusing."

- "Today's activity was difficult."

3) Evaluation of the chart and feedback

We first evaluate the helpfulness of in-class activities. Figure 1 shows the results of helpfulness of in-class activities categorized by weeks. Based on my past teaching experiences, I believe that students can learn better if 
Are Activities helpful for learning?

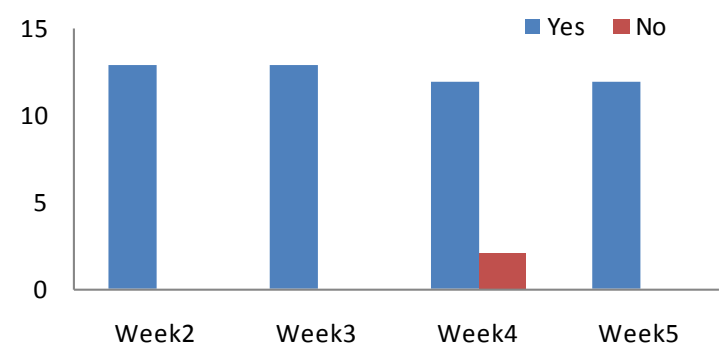

Figure 1. Helpfulness of in-class activities.

they participate more in the class, and thus, I decided to ask the students to provide feedback about these in-class activities. In this way, I was able to adjust the in-class activities for the following lectures.

Most students believed the in-class activities were very useful for learning experience. Based on these positive comments provided above, I believe most students believe the in-class activities were helpful and they could easily learn the class materials. They also stated that they had fun with these in-class activities and found them to be interesting. Some students mentioned that these in-class activities also taught them to work in groups and get to know each other better.

However, there were two students who did not really think the class activities were useful in the fourth week. This is because in the fourth week, I had introduced the students to the $\mathrm{C}^{++}$programming language, which is a completely new subject for most of them. From these comments, I learned that I should slow down my teaching speed, especially when I introduce new material to the students, so that the students wouldn't get lost so easily.

\subsection{Evaluation of Class Load}

1) Positive feedback

- "The class materials are just about right. You are very helpful."

- "I think the flow of materials is just about right."

- "It's perfect the amount of materials we get."

- " "It is very interesting so it’s fun to learn."

- "The materials are challenging enough to learn."

2) Constructive feedback

- "Provide more examples."

- "A little bit too much material. I am just slow at learning."

- "A little bit confusing at one time, but I started to comprehend at the end."

- "Sort of too much. I can understand something but not everything."

- "I think you flooded me with too much materials."

- "Explain more of what the computer is doing in response to our commands."

- "This is too much. I don't want to learn more in depth."

3) Evaluation of the chart and feedback

Figure 2 shows the results for the class load. I was curious to know whether I had introduced too much material in the class, so that I could adjust the in-class load for future classes.

As shown in the Figure 2, most of the students believe the class loads were about right (the bar shown in red). From these positive comments, I concluded that most of the students believed that the flow was reasonable and the concepts introduced in my class were very interesting.

However some of the students believed that I still introduced too much material. The reason is that some students believed that I should have provided more examples right after I introduced the syntax of the C++ programming language, so they wouldn't get lost when they started their in-class activities. Others were slow learners and learned only some of the material, but not everything. One student seemed scared at the beginning and was not receptive about learning programming since this was his first time. In response to these comments, I believe that I definitely need to provide more examples during the lectures and to make sure the students understand the material before I move on to the in-class activities. 


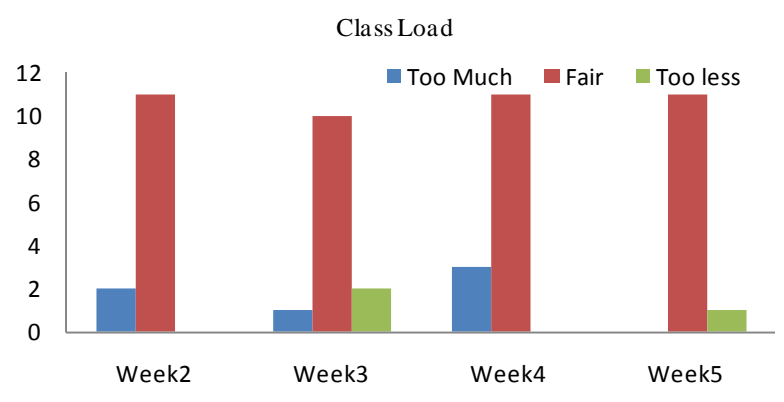

Figure 2. Evaluation of class load.

In addition, Figure 2 shows how I constantly adjusted my next class topics, based on the students' feedback in the previous weeks. For example, all of the students believed that the amount of contents given in class was a little bit too much in the second week, so I tried to change my lecture slides for the third week. In the third week, some of the students believed the class load was a little bit less, so I appropriately adjusted my class materials. Again, some students felt the course load was a little bit too much in the fourth week. I adjusted it one more time for the fifth week and everyone was satisfied. The most challenging part is to estimate the time it takes for the students to learn. I know that the only solution for this issue is to gain more teaching experience and more feedback from the students by having evaluation forms handy.

\subsection{Evaluation of Level of Difficulty}

1) Positive feedback

- "It's easy to comprehend."

- "The material is challenging and I learned a lot."

- "Today the material was generally easy to understand."

- "The flow of class is good, and materials is about right."

2) Constructive feedback

- "I am somewhat understanding it, not understanding everything."

- "A little bit too hard."

- "Just a little bit too hard, because it was a little fast."

- "A little too hard but I can manage."

- "I am still confused and don’t know what to do."

- "It's just too hard."

3) Evaluation of the chart and feedback

Figure 3 shows the results for level of difficulty of the class. Most of the students believed the materials were about right throughout for all of the weeks. Some of the positive comments indicate that my students believed the amount of class materials introduced was about right.

However, some of the students thought the class materials were still difficult, as indicated by the above constructive comments. As these comments indicated, some of the students understood the concepts partially because it was somewhat too hard for them. Some students pointed out that I introduced the new ideas too fast for them and didn't give them enough time to comprehend. Most of these comments were from the fourth week, when I began to teach them how to write a $\mathrm{C}^{++}$program. In the fifth week, I gave them a longer review of what we had done at a slower pace. In addition, I gave them another in-class activity which was similar to that in the fourth week so that they could have a second opportunity to learn what was presented in the previous week. Thus, in the fifth week, most of the students believed the class materials were not that difficult compared to the fourth week. Reinforcing the same concept by adding another in-class activity definitely helped them to pick up the material easier. I do think that activities that relate to a certain concept can improve students' learning experience.

In addition, Figure 3 shows that I am adjusting the level of difficulty based on students' feedback. I lowered the difficulty of my lectures when students reflected to me that the new introduced information was too hard. Similarly, I added more challenging material in the next class when they felt the material was too simple. I believe that it is very important for me to pay close attention to the students' feedback, in order to help students to learn successfully. 


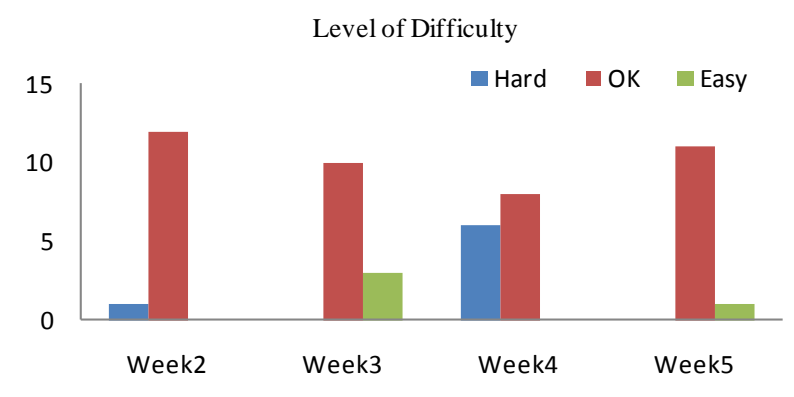

Figure 3. Evaluation for the level of difficulty.

\subsection{Evaluation System for Courses and Instruction (ESCI) Ratings for the Overall Class}

1) Positive feedback

a) "I like every single field. It was interesting."

b) "I like all the fields introduced in class. They were interesting to learn."

2) Constructive feedback

a) "I don’t like writing because I am not very interested in English writing-type activities."

b) "I didn't like the statistics because it was boring."

c) "I didn't like English because I am more like a math person. I want to study something related to math because I like math."

d) "I didn't like computer networks because it was more confusing for me and wasn't much interesting."

3) Evaluation of the chart and feedback

Figure 4 represents the Evaluation System for Courses and Instruction (ESCI) ratings for the overall course. Only 12 out of the 22 high school students responded to the teaching evaluations and, therefore, the results might not reflect the overall perception of students enrolled in the class.

From Figure 4, we see that most of the students believe the class handouts were well-prepared and organized, that the level of reading is fair and easy, and the level of math is fair and easy. Because the goal of the SST Program is to inspire high school students to become more interested in Science and Engineering, I tried to avoid introducing very complicated or difficult Mathematics. Moreover, instead of assigning some heavy research papers for them to read, I only assigned newspaper articles or text from the Web for them to read. Most of the students told me that they enjoyed the in-class activities and had a great time in learning programming languages in my class.

In addition, this course was the first time that I actively utilized more in-class participation. From the SST training sessions, I learned that class participation was the key that will lead to students' learning success. As a result, I encouraged my students to become more involved in the class. The students' positive feedback further confirmed that these in-class activities were beneficial for learning the class material. Most of the students thought the topics were exciting and believed that it would be beneficial for their future careers. Lastly, some students were eager to learn more by extending the duration of the program.

In one of my sessions, I asked the students to read some newspaper articles, write a brief summary, and present to the class what they had read. Some of them did not like this part and mentioned that I could perhaps omit this activity in the future. However, in the future I would still assign similar writing and reading activities to my students since it is essential to learn how to analyze articles and practice writing skills. I was influenced by my advisor and I remember he once told me: "The most important course you take at the university is the writing class." He believed that no matter how smart you are, or how successful you would be in conducting your research, you still need to present your work in an organized way that everyone can understand. I agreed with his proposition, which is why I tried to design this in-class activity with some writing exercises. Perhaps, in the future, I would try to design these in-class activities in more interactive ways, such as having students to pick a topic they like, work on writing a sample abstract, and present it to the class. I believe that my students will enjoy these kinds of in-class activities more than reading and writing summaries in the engineering area.

In conclusion, I have learned how to adjust my class load, level of difficulty, and in-class activities, based on the students' feedback. Once I tried to encourage more in-class participation, students were not afraid to ask questions towards the end of the class. Although it was a very challenging task to design the class by 


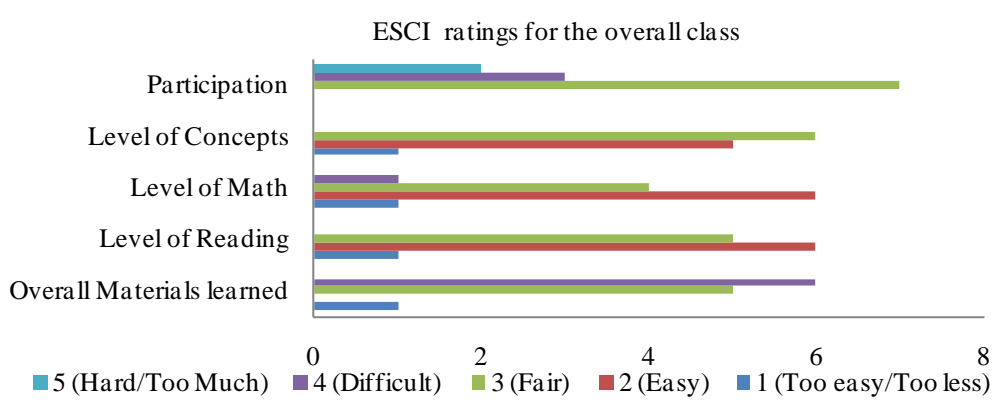

Figure 4. ESCI ratings for the overall class.

incorporating everyone's feedback, I certainly made my best effort to guide them learn throughout all five sessions. I believe regular evaluations in my future class will definitely help improve and sharpen my teaching skills.

\section{Analysis and Discussions}

First, I noticed from the beginning of the class, I was not familiar with my students' prior knowledge, and thus, I had overestimated their knowledge of mathematics. I discovered this problem in the in-class activity during the first week. The students came from different educational backgrounds, and some of them did not have adequate prior knowledge before taking my class. I had to change my teaching style. Thus, I began each class by reviewing some basic materials that I expected them to know and tried to spend more time on reviewing unfamiliar concepts. This helped my students to connect the new material easier with their prior knowledge. After I changed my way of teaching, the students started to pick up the new material without difficulty and they all had fun learning in this way.

Second, because this course was very flexible in the amount of lecture materials, there was no pressure as to "how much material" students should learn from my class. In other words, we do not need to pass on all of our knowledge to the students, but rather to inspire them in the field of science or engineering. As a result, I asked my students to do a class assessment before they left the classroom each time, and this helps me to adjust my topics accordingly for the following week. For example, before I started my first session, I asked my students to fill out pre-course surveys, so that I could better determine their abilities on performing these digital technologies. As a result, I saw that most of my students wanted to learn how to write computer programs. After I saw their comments, I changed the rest of my sessions so that they could have some experience with writing programs in C++. I learned how to change my class materials dynamically based on the students' feedback and abilities, which I believe was a valuable experience for me. I believe that the more feedback that my students provide, the better I can structure my lectures.

Moreover, I tried to foster more in-class participation for each of my sessions. For instance, I constructed a technology-supported environment to motivate my students' to participate. In addition, I asked students to pair up and do an activity together right after I finished my lecture. By doing so, I had made myself a creative instructor for designing these in-class activities. I believe that both ways are very helpful for students to activate participate in the class, to think critically, and to see how much they understood the newly introduced concepts. In other words, I consider this as the best way for students to absorb new material faster. As a result, I saw that my students tended to ask questions more frequently during these group activities, because many of them did not feel comfortable speaking in front of the class. This experience was very valuable for me since it allowed me to realize that students learn material more successfully through in-class activities.

Furthermore, my students like about my in-class activities in aiding their ability to learn a certain concept, my fair amount of course load that was adjusted on a weekly basis, and the level of difficulty that was altered constantly based on their weekly feedback. The ESCI chart reflected that the overall materials learned were average, and the level of concept, math and reading were all fair. The evaluations in this course have greatly helped me to figure out my strengths and weaknesses in my teaching career.

In conclusion, I especially think that getting feedback from the previous sessions helped me to organize my class materials and to design more interesting activities for the next session. In addition, obtaining student feedback has allowed me to assist students to learn new material more effectively. In other words, not only I teach 
my students class materials, but they also teach me on how to become a better instructor. The only way to become a good instructor is to engage in lifetime learning. The more feedback and suggestions I can obtain from the students, the better instructor I will be in the future, and that's the fundamental key for effective teaching and learning.

\section{Conclusion}

Having students to actively engage in the classroom stimulates their learning motivations, and makes the classroom experience more enjoyable. As a result, I have introduced my experiences in developing a technologysupported learning environment to increase students' learning motivations and achieve collaborative learning.

The first benefit of such pedagogy was that it helped me to become an excellent educator. I grew from an amateur to a much more experienced instructor, who could make a class more interesting and meaningful. I learned how to utilize the technology to create practical in-class activities to encourage more class participation and dynamically adjusting materials based on students' backgrounds. I truly believed that the time I spent on evaluating the students' feedback was a critical part, because their evaluations showed me how I could improve my teaching methods. In addition, I learned that continued self-assessment was an important key to becoming a better instructor.

Second, my pedagogy allows my students to become more active in the class, to obtain more learning knowledge, to increase their learning motivations, to pay greater attention in my class, and ultimately to simulate their interests in learning inside and outside of the class. As a result, it encourages students to engage more actively in the class and lead to greater learning in the classroom. In addition, once the students become engaged, instructors will become more motivated toward teaching.

Third, the benefit of such pedagogy is that in order to become a better instructor, I have to strive continuously to improve or adjust my teaching methods according to the students' reactions and suggestions to improve my overall teaching quality. Because students have different educational backgrounds, I have to change my teaching methods regularly to help students learn more effectively. For me, this is the most interesting and rewarding part because facing these different challenges allows me to obtain greater accomplishments. I learn that I must continually evaluate and improve myself to become an excellent instructor who can help students to learn better, more effectively, and more thoroughly.

\section{Acknowledgements}

I would like to thank to all the students in "School of Scientific Thought (SST)" program for their involvement and feedback in this study. In addition, I would like to thank to the SST mentor, Wendy Ibsen, for arranging four wonderful training sessions to sharpen my teaching skills.

\section{References}

Barkley, E. F., Cross, K. P., \& Major, C. H. (2014). Collaborative Learning Techniques: A Handbook for College Faculty. Hoboken, NJ: John Wiley \& Sons.

Barron, B. (2003). When Smart Groups Fail. The Journal of the Learning Sciences, 12, 307-359. http://dx.doi.org/10.1207/S15327809JLS1203 1

Bruffee, K. A. (1999). Collaborative Learning: Higher Education, Interdependence, and the Authority of Knowledge. Baltimore, MD: Johns Hopkins University Press.

Caldwell, J. E. (2007). Clickers in the Large Classroom: Current Research and Best-Practice Tips. CBE-Life Sciences Education, 6, 9-20. http://dx.doi.org/10.1187/cbe.06-12-0205

Dillenbourg, P., Baker, M. J., Blaye, A., \& O’Malley, C. (1995). The Evolution of Research on Collaborative Learning. In Learning in Humans and Machine: Towards an Interdisciplinary Learning Science (pp. 189-211). Oxford: Elsevier.

Edgerton, R. (1997). Higher Education White Paper. Pew Charitable Trusts.

Fisher, K. (2010). Technology-Enabled Active Learning Environments: An Appraisal (No. 2010/7). OECD Publishing. http://dx.doi.org/10.1787/5kmbjxzrmc0p-en

Gabbert, B., Johnson, D. W., \& Johnson, R. T. (1986). Cooperative Learning, Group-to-Individual Transfer, Process Gain, and the Acquisition of Cognitive Reasoning Strategies. The Journal of Psychology, 120, 265-278. http://dx.doi.org/10.1080/00223980.1986.10545253 
Gokhale, A. A. (1995). Collaborative Learning Enhances Critical Thinking.

Hake, R. R. (2001). Lessons from the Physics-Education Reform Effort. arXiv preprint physics/0106087.

Hertel, J. P., \& Millis, B. J. (2002). Using Simulations to Promote Learning in Higher Education: An Introduction. Stylus Publishing, LLC.

Kirschner, P. A. (2001). Using Integrated Electronic Environments for Collaborative Teaching/Learning. Learning and Instruction, 10, 1-9. http://dx.doi.org/10.1016/S0959-4752(00)00021-9

Kuh, G. D., \& Hu, S. (2001). The Relationships between Computer and Information Technology Use, Selected Learning and Personal Development Outcomes, and Other College Experiences. Journal of College Student Development, 42, $217-232$.

McLoughlin, C., \& Luca, J. (2000). Cognitive Engagement and Higher Order Thinking through Computer Conferencing: We Know Why but Do We Know How. In Flexible Futures in Tertiary Teaching, Proceedings of the 9th Annual Teaching Learning Forum (pp. 2-4).

Meyers, C., \& Jones, T. B. (1993). Promoting Active Learning: Strategies for the College Classroom. San Francisco, CA: Jossey-Bass Inc.

Newman, D. R., Webb, B., \& Cochrane, C. (1995). A Content Analysis Method to Measure Critical Thinking in Face-toFace and Computer Supported Group Learning. Interpersonal Computing and Technology Journal, 3, 56-77.

Pascarella, E. T., \& Terenzini, P. T. (2005). How College Affects Students (Vol. 2). In K. A. Feldman (Ed.). San Francisco, CA: Jossey-Bass.

Pollock, S. J. (2006). Transferring Transformations: Learning Gains, Student Attitudes, and the Impacts of Multiple Instructors in Large Lecture Courses. 2005 Physics Education Research Conference, 818, 141-144.

Sharan, S. (1980). Cooperative Learning in Small Groups: Recent Methods and Effects on Achievement, Attitudes, and Ethnic Relations. Review of Educational Research, 50, 241-271. http://dx.doi.org/10.3102/00346543050002241

Shulman, L. S. (2002). Making Differences: A Table of Learning. Change: The Magazine of Higher Learning, 34, 36-44. http://dx.doi.org/10.1080/00091380209605567

Sills, T., Digby, A., \& Russ, P. (1991). Cooperative Learning: A Guide to Research. New York: Garland.

Srinivas, H. (2014). Collaborative Learning. http://www.gdrc.org/kmgmt/c-learn

Stahl, G., Koschmann, T., \& Suthers, D. (2006). Computer-Supported Collaborative Learning: An Historical Perspective. In Cambridge Handbook of the Learning Sciences (pp. 409-426).

Vygotsky, L. S. (1980). Mind in Society: The Development of Higher Psychological Processes. Cambridge, MA: Harvard University Press. 
Scientific Research Publishing (SCIRP) is one of the largest Open Access journal publishers. It is currently publishing more than 200 open access, online, peer-reviewed journals covering a wide range of academic disciplines. SCIRP serves the worldwide academic communities and contributes to the progress and application of science with its publication.

Other selected journals from SCIRP are listed as below. Submit your manuscript to us via either submit@scirp.org or Online Submission Portal.
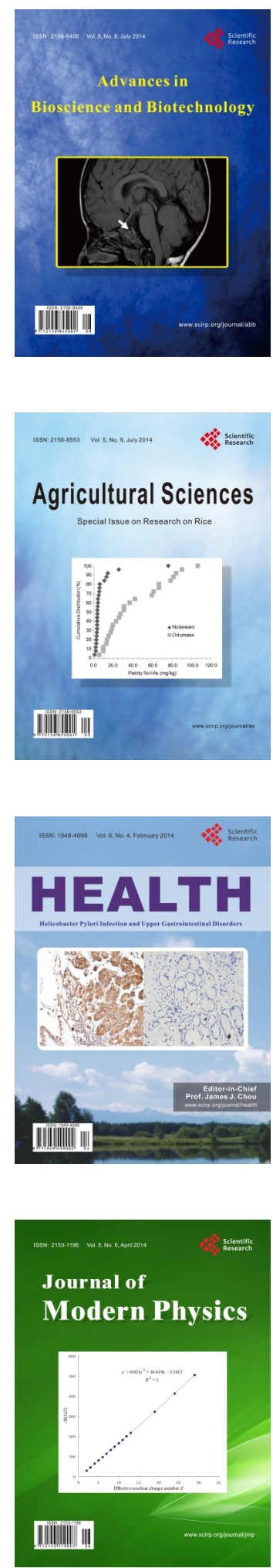
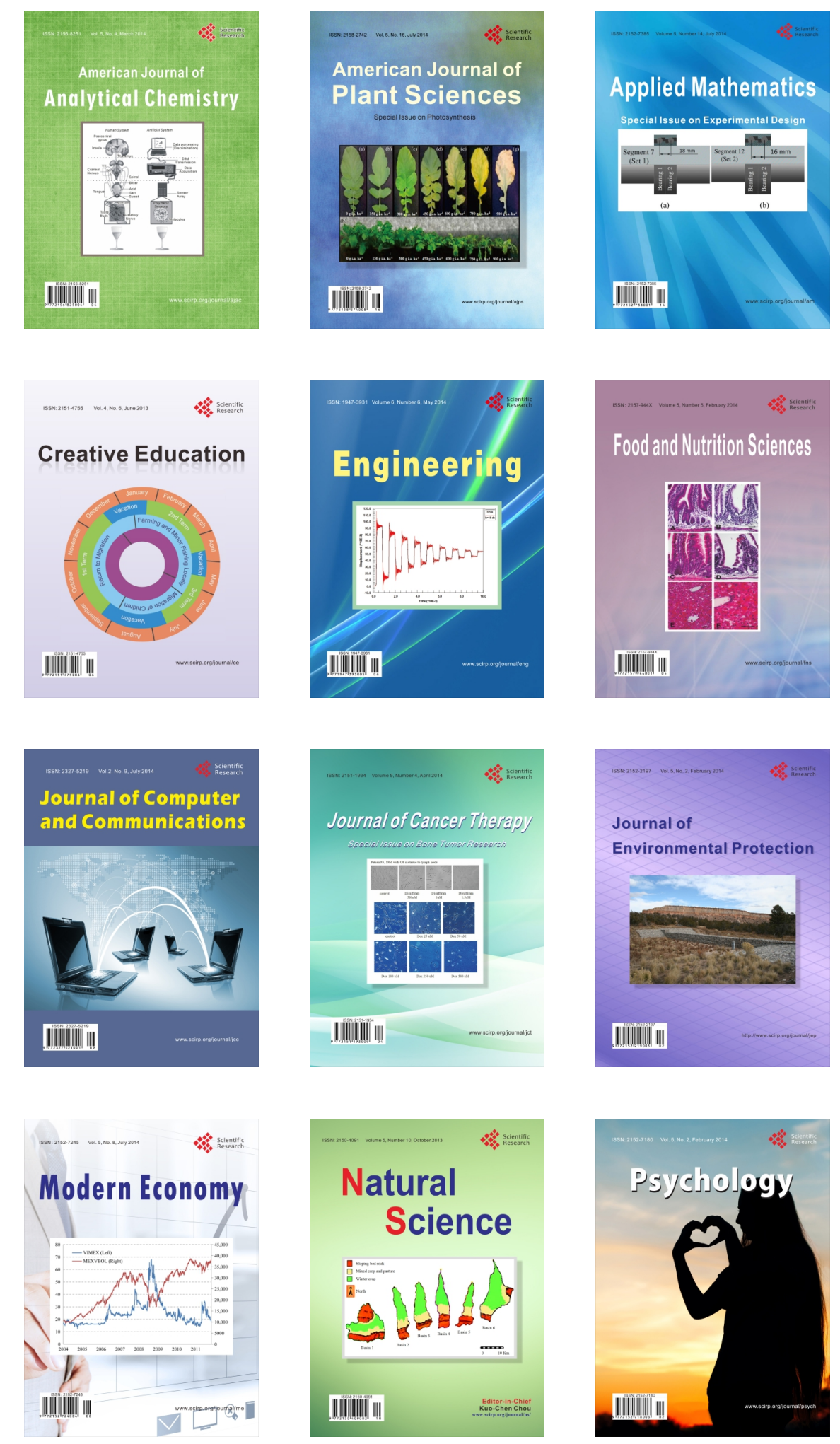